\title{
Diversidade e estrutura genética de populações de Varronia curassavica Jacq. em restingas da Ilha de Santa Catarina
}

HOELTGEBAUM, M.P. ${ }^{*}$; BERNARDI, A.P.'; MONTAGNA, T.'; REIS, M.S.1

Universidade Federal de Santa Catarina, Centro de Ciências Agrárias, Depto. Fitotecnia, Núcleo de Pesquisas em Florestas Tropicais - NPFT, Rod. Admar Gonzaga 1.346, Itacorubi, CEP: 88034-001, Florianópolis/SC - Brasil. *Autor para correspondência: mphmarcia@gmail.com.br

RESUMO: Varronia curassavica Jacq. (Boraginaceae) está presente na vegetação de restinga e apresenta relevantes propriedades medicinais. A espécie é explorada especialmente por comunidades locais e pela indústria farmacêutica, porém, carece de informações ecológicas e genéticas a seu respeito. Nesse contexto, o estudo foi conduzido com o objetivo de caracterizar a diversidade genética de três populações de $V$. curassavica em áreas de restinga na llha de Santa Catarina. Foram coletadas folhas de 50 indivíduos adultos em cada uma das três áreas de estudo e as frequências alélicas das populações foram obtidas a partir de 14 locos alozímicos. Foram encontrados 25 alelos distintos nas três populações, sendo dois alelos exclusivos. As populações apresentaram diversidade genética média de 0,111 e índice de fixação médio de $-0,060$ (-0,273 até 0,222). Os níveis de diversidade são intermediários, semelhantes aos exibidos por espécies da mesma família ou de características ecológicas semelhantes. Os índices de fixação foram todos significativos e discrepantes entre as populações, sendo que duas delas apresentaram excesso de heterozigotos. A divergência genética interpopulacional foi significativa e igual a 0,079 , considerada moderada e sugerindo efeitos de subdivisão populacional. Os níveis de diversidade genética encontrados e a redução populacional causada pela redução e fragmentação dos habitats em que a espécie ocorre sugerem medidas de conservação ex situ e demandam maior rigor na proteção legal de áreas de proteção permanente.

Palavras-chave: conservação, erva-baleeira, espécie medicinal, tamanho efetivo.

\begin{abstract}
Genetic diversity and structure of Varronia curassavica Jacq. populations in the restinga of Santa Catarina Island. The Varronia curassavica Jacq. (Boraginaceae) is present in restinga vegetation and shows relevant medicinal properties. The species is exploited by local communities and by the pharmaceutical industry; however, it lacks ecological and genetic information. Thus, this study aimed to characterize the genetic diversity of three $V$. curassavica populations in restinga areas of Santa Catarina Island. Leaves of 50 adult individuals were sampled in each of the three study areas and the allelic frequencies were obtained from 14 allozyme loci. Twenty-five different alleles were found in the three populations, two of them being exclusive. The populations showed, on average, a genetic diversity of 0,111 and a fixation index of $-0,060(-0,273$ to 0,222$)$. The diversity levels are intermediary, similar to those ones owned by species of the same family or with similar ecological traits. The fixation indexes were all significant and discrepant among the populations, with two of them showing excess of heterozygotes. The genetic divergence among populations was significant and equal to 0,079 , which is considered moderate and suggests effects of population subdivision. The levels of genetic diversity found and the population decrease caused by reduction and fragmentation of habitats in which the species are present implies in ex situ conservation measures and a higher enforcement of the legal preservation of permanent protected areas.
\end{abstract}

Keywords: conservation, effective size, "erva-baleeira", medicinal species. 


\section{INTRODUÇÃO}

Varrronia curassavica Jacq. (Boraginaceae) é uma espécie perene, arbustiva que apresenta ampla distribuição. Pode ser encontrada desde a América Central até o sul do Brasil, sendo característica da restinga litorânea, do Ceará até o Rio Grande do Sul (Smith, 1970; Falkenberg, 2012). Em Santa Catarina é comumente encontrada em restingas subarbustivas ou arbustivas, crescendo na duna frontal, ou em dunas internas e planícies arenosas enxutas, e pode ser ainda raramente encontrada em solos úmidos nas capoeiras da Floresta Ombrófila Densa (Smith, 1970).

A espécie apresenta relevante importância medicinal, sendo utilizada popularmente por suas propriedades anti-inflamatória, analgésica e cicatrizante (Lorenzi \& Matos, 2008), além de ser considerada também como antiulcerogênica, antimicrobiana e com propriedades tônicas (Panizza, 1997; Passos et al., 2007). Pesquisas realizadas com a espécie concluíram que o efeito anti-inflamatório deve-se à presença do princípio ativo a-humuleno (Medeiros et al., 2007), encontrado principalmente nas folhas. As atividades anti-inflamatórias e analgésicas têm sido comprovadas por estudos farmacológicos, e despertado cada vez mais o interesse da comunidade científica, sendo seus compostos alvo de diversos estudos (Velde et al., 1982; Basile et al., 1989; Lins et al., 1990; Sertié et al., 1991; Carvalho Junior et al., 2004; Gomes, 2010; Ming et al., 2012). Além de estar incluída na Relação Nacional de Plantas Medicinais de Interesse ao Sistema Único de Saúde - RENISUS (Brasil, 2009), há por parte da indústria farmacêutica um crescente interesse na obtenção de folhas da espécie para ser usada como matéria-prima na fabricação de medicamentos (Montanari, 2011).

Contudo, a obtenção de medicamentos fitoterápicos depara-se com a dificuldade de obtenção de matéria-prima, sendo o extrativismo ainda a principal forma de obtenção de plantas medicinais (Lapa, 2006). Apesar de o extrativismo possibilitar geração de renda para muitas comunidades e agricultores familiares, a pressão econômica pode tornar o processo extrativista predatório (Reis \& Siminski, 2012). Reduções de variabilidade genética associadas a diferentes intensidades de processos extrativistas já vem sendo relatadas para várias espécies (vide Sebbenn et al., 2008; Silva \& Reis, 2010; Ratnam et al., 2014). Este fato aliado à diminuição do tamanho das populações naturais, que vem ocorrendo principalmente com o avanço dos empreendimentos imobiliários em ambientes de restinga, pode representar uma ameaça à conservação da variabilidade genética da espécie.

A manutenção da variabilidade é a base da conservação de espécies (Frankham, 2005;
Kahilainen et al., 2014) e, portanto, o conhecimento de seus níveis e distribuição é fundamental para o estabelecimento de práticas de uso sustentável e conservação das mesmas (Reis, 1996; Frankham, 2003; Neel \& Ellstrand, 2003). Neste sentido, estudos sobre diversidade e estrutura genética de populações de plantas medicinais, bem como a relação destes com o manejo das mesmas se fazem necessários. São exemplos disso os estudos de Mariot et al. (2002), Steenbock \& Reis (2004), Bertoni et al. (2010), Baldauf et al. (2013) e Harish et al. (2014).

Apesar da sua importância, estudos relacionados à genética são escassos para a espécie. Até o momento, pode-se encontrar informações em Coleman (1982), que estudou o número de cromossomos de 54 espécies de angiospermas, dentre elas a $V$. curassavica e a categorizou como diplóide, com $n=x=9$, e em Figueira et al. (2009), que desenvolveram oito locos microssatélites altamente polimórficos para a espécie.

Diante deste cenário, este trabalho teve como objetivo conhecer a diversidade genética de populações de $V$. curassavica em áreas de restinga na llha de Santa Catarina. Especificamente, buscou adaptar um protocolo de sistemas isoenzimáticos para a espécie, caracterizar a diversidade genética intra e interpopulacional das populações, estimar índices de fixação e obter estimativas do tamanho efetivo populacional visando contribuir para o conhecimento acerca da diversidade genética da espécie e de possibilidades de conservação para a mesma em ambiente de restinga.

\section{MATERIAL E MÉTODO \\ A Espécie}

Varronia curassavica Jacq., pertence à família Boraginaceae (Smith, 1970). São consideradas para a espécie as sinonímias $C$. curassavica (Jacq.) Roem. \& Schult. e Cordia verbenacea (DC.) (Falkenberg, 2012). Popularmente é mais conhecida como erva-baleeira, caramona, salicina ou camarinha (Melo et al., 2008; Falkenberg, 2012). A espécie é heliófita, perene, de hábito arbustivo, bastante ramificado, podendo atingir de 1 a 2 metros de altura. Pode florescer em qualquer época do ano, com maior intensidade durante a primavera e verão (Montanari, 2011). Apresenta entomofilia, sendo moscas, abelhas e borboletas seus principais polinizadores e, sua dispersão se dá principalmente por aves (Montanari, 2011).

A exsicata da espécie (ramo florido) está depositada no herbário FLOR da Universidade Federal de Santa Catarina, sob o voucher FLOR 
20081, coletada em maio de 2014, na restinga da Joaquina - Florianópolis/SC.

\section{Áreas de Estudo}

O estudo foi realizado em três populações de $V$. curassavica, localizadas em áreas distintas de formação de restinga, ao sul da llha de Santa Catarina (Figura 1). A população da Joaquina $\left(27^{\circ} 37^{\prime} 46.19^{\prime \prime}\right.$ s e $48^{\circ} 27^{\prime} 1.59^{\prime \prime}$ ) $)$ está inserida no Parque Municipal das Dunas da Lagoa da Conceição - PMDLC, que possui área aproximada de 563 ha (Cecca, 1997), com extensão de 3,5 km e largura média de 1,2 km (Scherer, 2004). A área do PMDLC compreende um mosaico vegetacional, com fitofisionomia predominante herbácea arbustiva, associadas à duna frontal, dunas interiores e baixadas alagadas, úmidas e secas (Bresolin,
1979). A população do Campeche ( $27^{\circ} 41^{\prime} 6.07^{\prime \prime} \mathrm{S}$ e $48^{\circ} 28^{\prime} 50.20^{\prime \prime} \mathrm{)}$ ) encontra-se em uma área de 121 ha, contínua ao PMDLC. O campo de dunas situa-se ao longo da praia do Campeche, numa faixa estreitada pela pressão imobiliária. A vegetação predominante é herbácea arbustiva, com alguns trechos formados por arvoretas entre dunas, formando dossel. A terceira área de estudo está localizada no Pântano do Sul (27 $46^{\prime} 51.80^{\prime \prime} S$ e $\left.48^{\circ} 31^{\prime} 9.68^{\prime \prime} \mathrm{O}\right)$, mais ao sul da llha e não contínua do PMDLC. O campo de dunas desta área possui 24,2 ha e a cobertura vegetal apresenta-se mais densa, com predomínio de espécies arbustiva e arbóreas. Esta última, apesar de aparentemente ser mais conservada em termos de cobertura vegetal, encontra-se em um fragmento menor, sendo área verde de condomínios construídos no seu entorno.

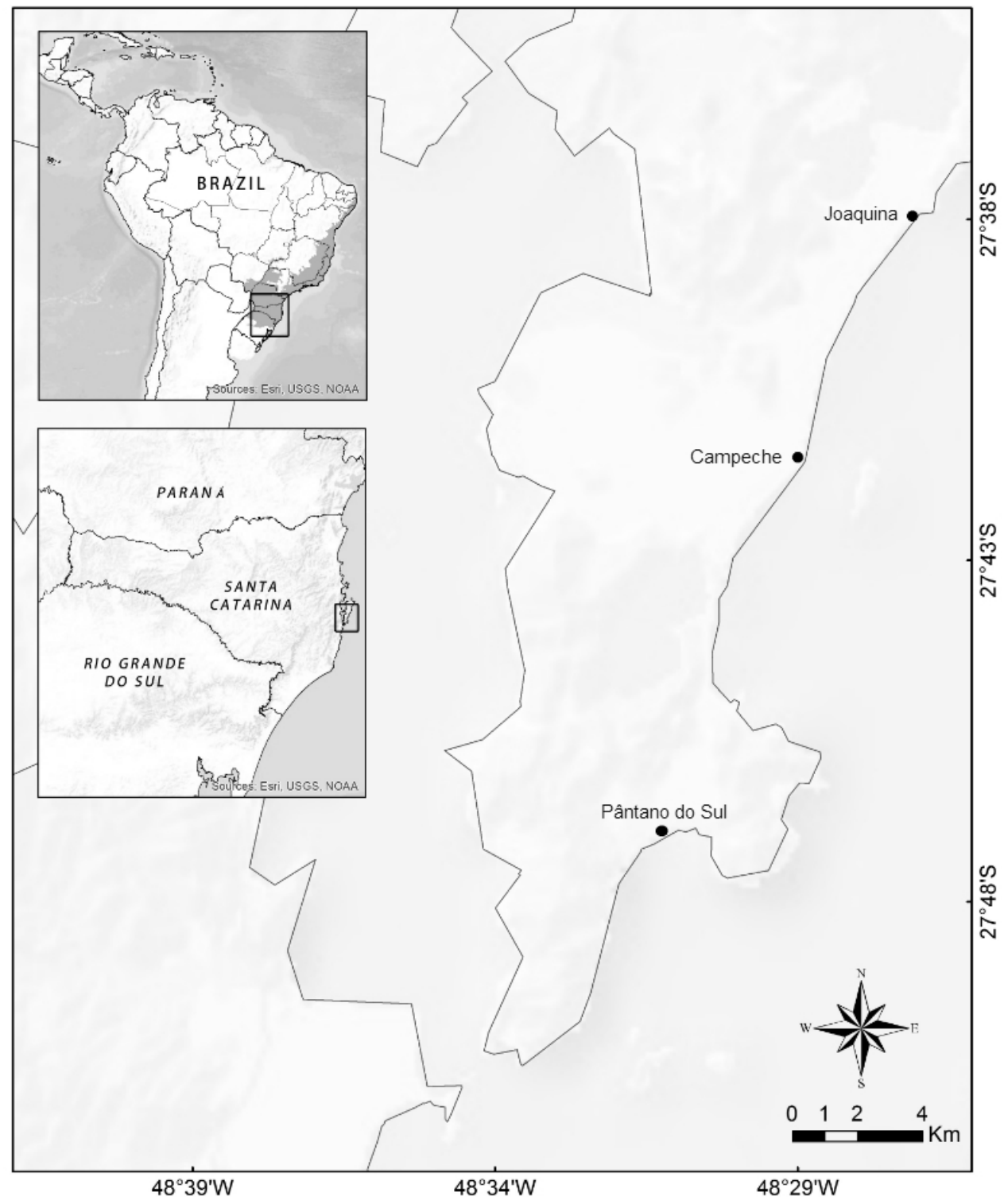

FIGURA 1. Mapa com a localização das três áreas de estudo. A distância mínima entre as áreas é de $6 \mathrm{~km}$ (Campeche - Joaquina); e a máxima é de 18 km (Pântano do Sul -Joaquina). Entre as populações do Campeche e Pântano do Sul, a distância é de 11 km. 


\section{Amostragem}

Para cada população, foram coletadas amostras foliares provenientes de 50 indivíduos adultos, as quais foram armazenadas em sacos plásticos e acondicionadas em caixa térmica contendo gelo. Na sequência foram encaminhadas para o Laboratório de Fisiologia do Desenvolvimento e Genética Vegetal da UFSC - LFDGV, onde ficaram armazenadas por até dois dias em geladeira à temperatura de $5^{\circ} \mathrm{C}$.

\section{Procedimentos laboratoriais}

O processo de solubilização das enzimas foi realizado com auxílio do macerador automático Precellys ${ }^{\circledR} 24$. Em cada tubo de maceração (modelo Hard Tissue Grinding MK28), foram adicionados: aproximadamente $50 \mathrm{mg}$ de material foliar, 5 esferas de aço inoxidável, 0,4 $\mathrm{ml}$ de solução de extração $n^{0} 1$ (Alfenas et al., 1991) e cerca de 10 $\mathrm{mg}$ de polivinilpirrolidona (PVP 40). Os tubos foram agitados por 15" a 6700 RPM. O meio de suporte da eletroforese foi o gel de amido de milho (penetrose 30 a $13 \%$ ) e o sistema eletrodo-gel foi o citrato de morfolina, pH 6,1 (Cheliak \& Pittel, 1984; Alfenas et al., 1991). A Tabela 1 apresenta os sistemas isoenzimáticos testados e os selecionados, com base no polimorfismo e nitidez, para a caracterização das populações.

\section{Análises Estatísticas}

A partir das frequências alélicas obtidas foi estimado para cada população o número total de alelos, número médio de alelos por loco $(\hat{A})$, número efetivo médio de alelos por loco $\left(\hat{A}_{E}\right)$ pela equação $\hat{A}_{E}=1 /\left(1-\hat{H}_{E}\right)$, porcentagem de locos polimórficos $(\hat{P})$, heterozigosidade observada $(\hat{H} \circ)$ e heterozigosidade esperada $\left(\hat{H}_{E}\right)$, além do índice de fixação $(\hat{f})$. Alelos com frequência menor que $5 \%$ foram considerados raros, e alelos restritos à apenas uma população foram considerados exclusivos. A estrutura genética foi estimada a partir das estatísticas $\mathrm{F}$ de Wright (1951), utilizando o método de estimação de Weir \& Cockerham (1984). Também foram estimados os tamanhos efetivos populacionais $\left(\hat{\mathrm{N}}_{\mathrm{e}}\right)$, populacionais, de acordo com Vencovsky (1992), $\hat{\mathrm{N}}_{\mathrm{e}}=\mathrm{n} /(1+\hat{f})$, em que $n$ e o tamanho amostral e $\hat{f}$ o índice de fixação. Para a obtenção dos índices genéticos foram utilizados os programas FSTAT versão 2.9.3.2 (Goudet, 2002) e GDA versão 1.0 (Lewis \& Zaykin, 2002).

\section{RESULTADO E DISCUSSÃO}

\section{Diversidade genética e tamanho efetivo}

Os nove sistemas isoenzimáticos utilizados permitiram a interpretação de 14 locos, sendo oito deles polimórficos (Tabela 2). Foram encontrados 25 alelos distintos entre as três populações amostradas. As frequências alélicas foram heterogêneas entre as populações, sendo que dois alelos foram exclusivos para duas populações: o alelo um do loco SKDH

TABELA 1. Sistemas isoenzimáticos testados e selecionados (*), código e sigla das enzimas.

\begin{tabular}{|c|c|c|}
\hline Enzima & Código & Sigla \\
\hline Malato Desidrogenase* & EC 1.1.1.37. & $\mathrm{MDH}$ \\
\hline Superóxido Dismutase & EC 1.15.1.1. & SOD \\
\hline Peroxidase & EC 1.11.1.7. & PRX \\
\hline Xiquimato Desidrogenase* & EC 1.1.1.25. & SKDH \\
\hline Fosfoglucomutase* & EC 5.4.2.2. & PGM \\
\hline Diaforase & EC 1.8.1.4. & DIA \\
\hline Glutamato Oxaloacetato Transaminase & EC 2.6.1.1. & GOT \\
\hline Esterase* & EC 3.1.1.1 & EST \\
\hline Fosfogluco Isomerase* & EC 5.3.1.9. & PGI \\
\hline Fosfatase Ácida* & EC 3.1.3.2. & ACP \\
\hline Enzima Málica* & EC 1.1.1.40 & ME \\
\hline Nicotinamida Adenina Dinocleotídeo Desidrogenase & EC 1.6.99.3 & $\mathrm{NADH}$ \\
\hline Fosfatase Alcalina & EC 3.1.3.1 & ALP \\
\hline 6-Fosfogluconato Desidrogenase* & EC 1.1.1.44 & 6PGDH \\
\hline Glucose 6-Fosfato Desidrogenase & EC 1.1.1.49 & G6PDH \\
\hline Glicerato-2 Desidrogenase & EC 1.1.1.29 & G2DH \\
\hline Glutamato Desidrogenase & EC 1.4.1.3 & GTDH \\
\hline Isocitrato Desidrogenase* & EC 1.1.1.42 & $\mathrm{IDH}$ \\
\hline Leucina Aminopeptidase & EC 3.4.11.1 & LAP \\
\hline
\end{tabular}

Rev. Bras. PI. Med., Campinas, v.17, n.4, supl. III, p.1083-1090, 2015. 
para a população Campeche e alelo três do loco MDH2 para população Pântano do Sul. A população Joaquina apresentou três alelos raros (PGI1 alelo 2, ACP alelo 3 e MDH2 alelo 1), enquanto que um alelo raro foi encontrado na população Pântano do Sul (PGI1 alelo 2) e outro na população Joaquina (SKDH alelo 1) (Tabela 2).

As populações de $V$. curassavica (Tabela 3) apresentaram diversidade genética média $\left(\hat{H}_{E}\right)$ de 0,111 (de 0,098 até 0,126 ), $\hat{H}_{0}$ médio de 0,117 (de 0,085 até 0,143 ), bem como um $\hat{f}$ médio de $-0,060$ (de $-0,273$ até 0,222 ). Hamrick et al. (1992) apontam níveis de diversidade ligeiramente menores aos encontrados, para populações de espécies herbáceas perenes não-longevas $(\hat{P}=$ $29,8 \%, \hat{A}=1,39, \hat{A}_{E}=1,12$ e $\left.\hat{H}_{E}=0,098\right)$. Outros estudos com espécies da família Boraginaceae utilizando isoenzimas também revelaram níveis de diversidade semelhantes, ou ainda menores aos encontrados para $V$. curassavica. Chase et al. (1995), para 11 populações de Cordia alliodora, encontraram $\hat{P}, \hat{A}, \hat{A}_{E}, \hat{H}_{E}$ médios de $44 \%, 1,73$, 1,23 e 0,127 , respectivamente. Já Del Hoyo et al. (2012), para uma população de Glandora oleifolia, encontraram $\hat{P}, \hat{A}, \hat{H}_{E}$ e $\hat{H}_{0}$ de $30,8 \%, 1,69,0,098$ e 0,076 , respectivamente.

Os índices de fixação foram todos significativamente diferentes de zero e discrepantes entre as populações (Tabela 3 ). Duas populações apresentaram excesso de heterozigotos: Joaquina $(\hat{f}=-0,140)$ e Campeche $(\hat{f}=-0,273)$. Estudos de Taisma \& Varela (2005), realizados na Venezuela, demonstram que $V$. curassavica (citada no artigo como Cordia curassavica) é distílica e possui sistemas de autoincompatibilidade esporofítica, o que pode contribuir para os excessos de heterozigotos encontrados nestas populações, não se descartando também as hipóteses de cruzamentos preferenciais e de seleção em favor de heterozigotos. Esta última hipótese necessita ser melhor estudada por meio da análise da diversidade genética em indivíduos de diferentes idades. Tal análise permitiria inferir se possíveis variações nas frequências alélicas, e nos demais índices de diversidade genética, entre indivíduos de distintas idades suportam (ou não) a hipótese de seleção em favor de heterozigotos. Estudo semelhante já foi conduzido com Euterpe edulis (Conte et al., 2003).

$\mathrm{O} \hat{\mathrm{N}}_{\mathrm{e}}$ médio encontrado foi de 55 indivíduos, sendo 57 indivíduos para Joaquina, 39 para Pântano do Sul e 69 para Campeche. Os tamanhos efetivos de cada população refletem os índices de fixação das mesmas. Estes valores servem de base para o estabelecimento de tamanhos amostrais adequados, no caso de coletas de germoplasma de V. curassavica. Ademais, comparações posteriores dos tamanhos efetivos com as densidades reais de cada população também podem prover informações apuradas sobre a situação de conservação de cada população, bem como suas perspectivas futuras. O menor tamanho efetivo populacional $\left(\hat{\mathrm{N}}_{\mathrm{e}}\right.$ = 39), bem como o índice de fixação $(\hat{f}=0,222$; valor inesperdado para a uma espécie distílica), encontrado para Pântano Sul e pode estar refletindo, em parte, a restrição de tamanho populacional causada especialmente pela expansão imobiliária, o que as tornam mais suscetíveis a eventos estocásticos.

\section{Estrutura genética populacional}

As populações apresentaram índice de fixação total e médio dentro das subpopulações não significativos ( $\hat{F} I T=0,021$ e $\hat{F} I S=-0,063$, respectivamente). No entanto, a divergência genética interpopulacional ( $\hat{F}$ ST) foi significativamente maior do que zero $(0,079, p<0,05)$, podendo ser considerada moderada. Este resultado demonstra que cerca de $8 \%$ da variação alélica encontrada não é compartilhada pelas três populações, por conta de subdivisões. As diferenças no número e distribuição dos alelos entre as populações (Tabela 2 e Tabela 3 ) já indicavam divergência entre as mesmas. Segundo Govindaraju (1988), um dos principais fatores que determinam os níveis de fluxo gênico em populações vegetais são os mecanismos de polinização. Polinizadores que tem voos curtos podem favorecer uma maior divergência entre populações, como discutem Mariot et al. (2002). V. curassavica é polinizada principalmente por moscas, abelhas e borboletas (Montanari, 2011), todos insetos de voo curto e, além disso, a menor distância entre as populações é de $6 \mathrm{~km}$ (entre Joaquina e Campeche). Assim, o comportamento dos polinizadores, aliado à distância entre os fragmentos podem estar influenciando o F̂sT encontrado.

A análise das divergências par a par demonstrou haver maior similâridade entre as populações Joaquina e Pântano do Sul ( $\hat{F} S T=0,055$, $p<0,05)$, e que a população do Campeche é a menos similar do conjunto (Joaquina $\times$ Campeche $\hat{F} S T=$ 0,101, p<0,05; Pântano do Sul $\times$ Campeche F̂́sT = $0,086, p<0,05)$. De fato, estas divergências entre as populações podem ser percebidas nas frequências alélicas (Tabela 2). Tais resultados indicam uma tendência distinta daquela que se encontraria, caso houvesse isolamento por distância, reforçando a importância da fragmentação na definição da estrutura genética populacional atual.

Os índices de fixação foram discrepantes entre as populações, bem como os tamanhos efetivos, sugerindo a ação de fatores como seleção em favor de heterozigotos, cruzamentos preferenciais e diferentes históricos de distúrbios. A moderada divergência interpopulacional indica

Rev. Bras. PI. Med., Campinas, v.17, n.4, supl. III, p.1083-1090, 2015. 
TABELA 2. Frequências alélicas a partir de 14 locos alozímicos para três populações de Varronia curassavica Jacq. (Boraginaceae), em restingas da llha de Santa Catarina.

\begin{tabular}{|c|c|c|c|c|c|}
\hline Loco & Alelo & Joaquina & Pântano do Sul & Campeche & Total \\
\hline & $\mathrm{N}$ & 51 & 51 & 51 & \\
\hline \multirow[t]{3}{*}{ PGI1 } & 1 & 0,99 & 0,98 & 1 & 0,99 \\
\hline & 2 & 0,01 & 0,02 & 0 & 0,01 \\
\hline & $\mathrm{N}$ & 49 & 51 & 50 & \\
\hline \multirow{3}{*}{ PGI2 } & 1 & 0,67 & 0,716 & 0,82 & 0,74 \\
\hline & 2 & 0,08 & 0,147 & 0,13 & 0,12 \\
\hline & 3 & 0,25 & 0,137 & 0,05 & 0,14 \\
\hline \multirow{2}{*}{ EST } & $\mathrm{N}$ & 51 & 51 & 51 & \\
\hline & 1 & 1 & 1 & 1 & 1 \\
\hline \multirow{2}{*}{ PGM1 } & $\mathrm{N}$ & 51 & 51 & 51 & \\
\hline & 1 & 1 & 1 & 1 & 1 \\
\hline \multirow{2}{*}{ PGM2 } & $\mathrm{N}$ & 51 & 51 & 51 & \\
\hline & 1 & 1 & 1 & 1 & 1 \\
\hline \multirow{2}{*}{ PGM3 } & $\mathrm{N}$ & 51 & 51 & 51 & \\
\hline & 1 & 1 & 1 & 1 & 1 \\
\hline \multirow{2}{*}{ PGM4 } & $\mathrm{N}$ & 51 & 51 & 51 & \\
\hline & 1 & 1 & 1 & 1 & 1 \\
\hline \multirow{4}{*}{ ACP } & $\mathrm{N}$ & 40 & 38 & 38 & \\
\hline & 1 & 0,13 & 0,092 & 0 & 0,07 \\
\hline & 2 & 0,84 & 0,908 & 0,711 & 0,82 \\
\hline & 3 & 0,04 & 0 & 0,289 & 0,11 \\
\hline \multirow{3}{*}{ SKDH } & $\mathrm{N}$ & 51 & 51 & 51 & \\
\hline & 1 & 0 & 0 & 0,01 & 0,003 \\
\hline & 2 & 1 & 1 & 0,99 & 0,99 \\
\hline \multirow{3}{*}{ MDH1 } & $\mathrm{N}$ & 50 & 51 & 51 & \\
\hline & 1 & 0,55 & 0,79 & 0,863 & 0,74 \\
\hline & 2 & 0,45 & 0,21 & 0,137 & 0,26 \\
\hline \multirow{4}{*}{ MDH2 } & $\mathrm{N}$ & 51 & 50 & 51 & \\
\hline & 1 & 0,02 & 0,06 & 0 & 0,03 \\
\hline & 2 & 0,98 & 0,8 & 1 & 0,93 \\
\hline & 3 & 0 & 0,14 & 0 & 0,05 \\
\hline \multirow{3}{*}{ 6PGDH } & $\mathrm{N}$ & 44 & 30 & 48 & \\
\hline & 1 & 0,83 & 0,95 & 0,75 & 0,83 \\
\hline & 2 & 0,17 & 0,05 & 0,25 & 0,17 \\
\hline \multirow{3}{*}{ ME } & $\mathrm{N}$ & 50 & 50 & 51 & \\
\hline & 1 & 0,92 & 0,95 & 1 & 0,96 \\
\hline & 2 & 0,08 & 0,05 & 0 & 0,04 \\
\hline \multirow{2}{*}{ IDH } & $\mathrm{N}$ & 51 & 51 & 51 & \\
\hline & 1 & 1 & 1 & 1 & 1 \\
\hline
\end{tabular}

As populações apresentaram, em média, 22 alelos variando de 20 a 23 (Tabela 3). A porcentagem de locos polimórficos ( $(\hat{P})$ média foi de $41 \%$, variando entre populações de 29 a $50 \%$, o número médio de alelos por locos (Â) médio foi de 1,57 , variando de 1,43 até 2 e o número efetivo de alelos por locos $(\hat{A} E)$ médio foi de 1,18 , variando desde 1,15 até 1,21 . A variação observada na $\hat{P}$ é decorrente das variações que os alelos de baixa frequência apresentaram entre as três populações (Tabela 2). Tais variações podem ser reflexo da ação de deriva genética. $O \hat{A}$ foi sempre superior ao $\hat{A} E$, demonstrando que as frequências alélicas não estão igualmente distribuídas entre os alelos de um mesmo loco, e indicando a existência de alelos de baixa frequência. 
TABELA 3. Tamanho amostral $(n)$, tamanho efetivo $\left(\hat{\mathrm{N}}_{\mathrm{e}}\right)$, número de alelos (alelos), porcentagem de locos polimórficos $(\hat{P})$, número médio de alelos por locos $(\hat{A})$, número efetivo médio de alelos por locos $(\hat{A} E)$, heterozigosidade média esperada $\left(\hat{H}_{E}\right)$, heterozigosidade média observada $\left(\hat{H}_{0}\right)$ e índice de fixação $(\hat{f})$, em três populações de Varronia curassavica Jacq. (Boraginaceae), Ilha de Santa Catarina.* $p<0,05$.

\begin{tabular}{cccccccccc}
\hline População & $n$ & $\hat{\mathrm{N}}_{\mathrm{e}}$ & Alelos & $\hat{\mathrm{P}}$ & $\hat{\mathrm{A}}$ & $\hat{A} E$ & $\hat{H}_{E}$ & $\hat{H}_{O}$ & $\hat{f}$ \\
\hline Joaquina & 49 & 57 & 23 & 43 & 2,00 & 1,21 & 0,126 & 0,143 & $-0,140^{*}$ \\
Pântano do Sul & 48 & 39 & 23 & 50 & 1,64 & 1,16 & 0,109 & 0,085 & $0,222^{*}$ \\
Campeche & 50 & 69 & 20 & 29 & 1,43 & 1,15 & 0,098 & 0,124 & $-0,273^{*}$ \\
\hline Média & $\mathbf{4 9}$ & $\mathbf{5 5}$ & $\mathbf{2 2}$ & $\mathbf{4 1}$ & $\mathbf{1 , 5 7}$ & $\mathbf{1 , 1 8}$ & $\mathbf{0 , 1 1 1}$ & $\mathbf{0 , 1 1 7}$ & $\mathbf{- 0 , 0 6}$ \\
\hline
\end{tabular}

restrições no fluxo gênico entre as populações, possivelmente influenciada pelo comportamento dos polinizadores e pela distância entre as populações. Um melhor conhecimento sobre a biologia reprodutiva da espécie facilitará o entendimento acerca dos mecanismos geradores de divergência entre as populações.

Os níveis de diversidade genética encontrados e a redução populacional causada pela redução e fragmentação dos habitats em que a espécie ocorre sugerem medidas de conservação ex situ e um maior rigor na proteção legal de áreas de proteção permanente. A continuidade dos estudos, especialmente os relacionados à biologia reprodutiva e dinâmica demográfica da espécie, poderão contribuir para um melhor entendimento dos mecanismos que atuam na distribuição da diversidade genética e na manutenção das populações.

\section{AGRADECIMENTO}

Agradecemos à CAPES e ao CNPq, a concessão de bolsa; ao Núcleo de Pesquisas em Florestas Tropicais e ao Laboratório de Fisiologia do Desenvolvimento e Genética Vegetal, ao apoio logístico, aos colegas Lilian Machado e Joseph Ree, o apoio nas saídas de campo e laboratório, ao Willian Vieira, pelo mapa das áreas, e aos revisores pelas sugestões.

\section{REFERÊNCIAS}

ALFENAS, A.C. et al. Eletroforese de proteínas e isoenzimas de fungos e essências florestais. Viçosa: Editora da Universidade Federal de Viçosa, 1991. 242p.

BALDAUF, C. et al. Tapping latex and alleles? The impacts of latex and bark harvesting on the genetic diversity of Himatanthus drasticus (Apocynaceae). Forest Ecology and Management, v. 310, p. 434-441, 2013.

BASILE, A.C.; et al., Topical anti-inflammatory activity and toxicity of Cordia verbenacea. Fitoterapia. v. 60 , n. 3 , p. 260-263, 1989.

BERTONI, B.W. et al. Genetic diversity among natural populations of Mandevilla velutina. Horticultura Brasileira, v. 28, p. 209-213, 2010.
BRESOLIN, A. Flora da restinga da llha de Santa Catarina. Insula v.10, p.1-54. 1979.

CARVALHO Junior, P.M. et al. Chemical composition and antimicrobial activity of the essential oil of Cordia verbenacea DC. Journal of Ethnopharmacology, v. 95, p. 297-301, 2004.

CECCA. Unidades de conservação e áreas protegidas da Ilha de Santa Catarina: caracterização e legislação. Florianópolis: Insular, 1997. 160p.

CHASE, M.R. et al. Population Genetics of Cordia alliodora (Boraginaceae), a Neotropical. Tree 1. Genetic variation in natural populations. American Journal of Botany, v. 82, n. 4, p. 468-475. 1995.

CHELIAK, W. M.; PITTEL, J. A. Techniques for starch gel eletrophoresis of enzymes from forest tree species. Information Report Pi-X, Chalk River, v. 42, n. 1, p. 1-49, 1984.

COLEMAN, J. R. Chromosome numbers in angiosperms collected in the state of São Paulo. Revista Brasileira de Genética, v. 3, p. 533-549, 1982.

CONTE, R. et al. Genetic diversity and recruitment of the tropical palm, Euterpe edulis Mart., in a natural population from the Brazilian Atlantic Forest. Heredity, v. 91, p. 401-406, 2003.

DEL HOYO, A. et al. Population genetics and conservation of the extremely narrow Pyrenean palaeoendemic Glandora oleifolia (Boraginaceae). Plant Ecology \& Diversity, v.4, n.4, p.501-511, 2012.

FALKENBERG, M. B. Varronia curassavica. In: CORADIN, L.; SIMINSKI, A. e REIS, A. ed. Espécies Nativas da Flora Brasileira de Valor Econômico Atual ou Potencial Plantas para o Futuro - Região Sul. Brasília: Ministério do Meio, Biodiversidade 40, 2012. 936p.

FIGUEIRA, G. M. et al. Development and characterization of microsatellite markers for Cordia verbenacea (Boraginaceae), an important medicinal species from the Brazilian coast. Conservation Genetics, v. 11, n. 3, p. 1127-1129, 2009.

FRANKHAM, R. Genetics and conservation biology. C.R. Biologies, v.326, p.22-29, 2003.

FRANKHAM, R. Genetics and extinction. Biological conservation, v. 126, n. 2, p. 131-140, 2005.

GOMES, P. A. Óleo essencial da erva-baleeira (Cordia verbenacea L.) de áreas nativas. 2010. 69p. Dissertação (Mestrado - Concentração em Produção Vegetal). Centro de Ciências e Tecnologias Agropecuárias da Universidade Estadual Norte Fluminense Darcy Ribeiro, Rio de Janeiro.

GOUDET, J. FSTAT version 2.9.3 Switzerland: Institute of Ecology, 2002.

Rev. Bras. PI. Med., Campinas, v.17, n.4, supl. III, p.1083-1090, 2015. 
GOVINDARAJU, D.R. Relationship between dispersal ability and levels of gene flow in plants. Oikos, v. 52, p. 31-35, 1988.

HAMRICK, J.L. et al. Factors influencing levels of genetic diversity in woody plant species. New Forests, v. 6, p. 95-124, 1992.

HARISH, A.K.G. et al. Conservation genetics of endangered medicinal plant Commiphora wightii in Indian Thar Desert. Gene, v. 535, p. 266-272, 2014.

KAHILAINEN, A. et al. Conservation implications of species-genetic diversity correlations. Global Ecology and Conservation, v. 2, p. 315-323, 2014.

LAPA, F. S. Cordia curassavica (JACQ.) ROEM. \& SCHULT. Influência de fatores ambientais no crescimento e na produção de metabólitos. 2006. 59p. Dissertação (Mestrado em Biologia Vegetal). Universidade Federal de Santa Catarina, Florianópolis.

LEWIS, P. O.; ZAYKIN, D. GDA - Genetic Data Analysis: version 1.1 for Windows 95/NT. 2002. Disponível em: http://www.lewis.eeb.uconn.edu/lewishome. Acessado em: 10 de novembro de 2013.

LINS, A.P. et al. Two flavonois from Cordia verbenacea. Revista Latino-Americana de Química, v. 21, n. 2, p. 82, 1990.

LORENZI, H.; MATOS, F. J. A. Plantas medicinais no Brasil. Nova Odessa: Instituto Plantarum, 2008. 544 p.

MARIOT, A. et al. Genetic Diversity in Natural Populations of Piper cernuum. The Journal of Heredity, v. 93, n. 5, p. 365-369, 2002.

MEDEIROS, R. et al. Effect of two active compounds obtained from the essential oil of Cordia verbenacea on the acute inflammatory responses elicited by Ips in the rat paw. British Journal of Pharmacology, v. 151, p. 618-627, 2007.

MELO, S.; LACERDA, V.D. \& HANAZAKI, N. Espécies de restinga conhecidas pela comunidade do Pântano do sul, Florianópolis, Santa Catarina, Brasil. Rodriguésia, v. 59, n. 4 , p. $799-812,2008$.

MING, L.C. et al. Pesquisas agronômicas das plantas medicinais da Mata Atlântica regulamentadas pela ANVISA. Revista Brasileira de Plantas Medicinais, v.14, n.esp., p.131-137, 2012.

BRASIL, Ministério da Saúde. 2009. Relação de Plantas Medicinais de Interesse ao SUS. Disponível em: http:// portalsaude.saude.gov.br/index.php/cidadao/principal/ agencia-saude/noticias-anteriores-agencia-saude/3487. Acessado em 14 de agosto de 2014.

MONTANARI, I. Jr. Variabilidade genética em uma população de Cordia verbenacea DC. 2011. 88p. Tese (Doutorado - Concentração em Agronomia Horticultura). Universidade Estadual Paulista "Júlio de Mesquita Filho", Faculdade de Ciências Agronômicas, Botucatu.

NEEL, M.C.; ELLSTRAND, N.C. Conservation of genetic diversity in the endangered plant Eriogonum ovalifolium var. vineum (Polygonaceae). Conservation Genetics, v. 4, p. 337-352, 2003.

PANIZZA, S. Plantas que curam: cheiro de mato. $25^{a}$ ed. São Paulo: IBRASA,1997. 280 p.

PASSOS, G. F. et al. Antiinflammatory and anti-allergic properties of the essential oil and active compounds from Cordia verbenacea. Journal of Ethnopharmacology, v. 110, p. 323-333, 2007.

RATNAM, W. et al. Genetic effects of forest management practices: global synthesis and perspectives. Forest Ecology and Management, v. 333, p. 52-65, 2014.

REIS, M.S; SIMINSKI, A. Espécies Medicinais Nativas da Região Sul do Brasil. In: CORADIN, L.; SIMINSKI, A. e REIS, A. ed. Espécies Nativas da Flora Brasileira de Valor Econômico Atual ou Potencial Plantas para - Futuro - Região Sul. Brasília: Ministério do Meio, Biodiversidade 40, 2012. 936p.

REIS, M.S. Dinâmica da movimentação dos alelos: subsídios para conservação e manejo de populações naturais em plantas. Revista Brasileira de Genética, v. 19, n. 4, p. 37-47, 1996.

SCHERER, K.Z. Ecologia de Megacerus baeri (Pic, 1934) e Megacerus reticulatus (Sharp, 1885) (Coleoptera: Bruchidae) em duas espécies de Convolvulaceae (Ipomoea imperati e Ipomoea pes-caprae) nas dunas da Praia da Joaquina, Florianópolis, SC. 2004. 206p. Tese (Doutorado - Concentração em Biologia e Morfologia Animal), Universidade Federal do Rio Grande do Sul, Porto Alegre.

SEBBENN, A.M. et al. Modelling the long-term impacts of selective logging on genetic diversity and demographic structure of four tropical tree species in the Amazon forest. Forest ecology and management, v. 254, n. 2, p. 335-349, 2008.

SERTIÉ, J.A.A. et al. Pharmacological assay of Cordia verbanacea III: Oral and topic anti-inflammatory and gastrotoxicity of a crude leaf extract. Journal of Ethnopharmacology, v.31, p. 239-247, 1991.

SILVA, J.Z.; REIS, M.S. Effects of Different Simulated Management Intensities on The Genetic Diversity of a Heart-of-palm Tree Natural Population (Euterpe edulis Martius). Silvae Genetica, v. 59, n.5, p. 201 -210, 2010.

SMITH, L.B. Boragináceas. In: R. Reitz (ed.). Flora Ilustrada Catarinense. Itajaí: Herbário Barbosa Rodrigues, 1970.85p.

STEENBOCK, W.; REIS, M.S. Manejo de populações naturais de Espinheira Santa. In: REIS, M.S.; SILVA, S.R. (Orgs.). Plantas medicinais e aromáticas: Espinheira Santa. Brasília: Editora IBAMA, v.1, p.14561, 2004.

TAISMA, M.A.; VARELA, C.W. Sistema de compatibilidad en la especie distílica Cordia curassavica (JACQ.) R\&S (Boraginaceae). Interciencia, v. 30, n.7, p. 431-435. 2005.

VELDE, V.V. et al. Cordialin A and B, two new triterpenes from Cordia verbanacea DC. Journal of Chemical Society of Perkin Trans, v. 11, p. 2697, 1982.

VENCOVSKY, R. Análise de variância de frequências alélicas. Revista Brasileira de Genética, v. 15, n. 1, p. 53-60. Suplemento 1, 1992.

WEIR, B.S. \& COCKERHAM, C.C. Estimating F-statistics for the analysis of population structure. Evolution, v. 38, p. 1358-1370, 1984.

WRIGHT, S. The genetical structure of populations. Annals of Eugenics, v. 15, p. 395-420, 1951. 